\title{
Thyroid disorder in antenatal women in sub-himalayan region: a need for universal screening
}

\author{
Swati Dubey, Anup Pradhan*
}

Department of Obstetrics and Gynecology, Sikkim Manipal Institute of Medical Sciences, Tadong, Gangtok, Sikkim, India

Received: 21 May 2017

Accepted: 20 June 2017

*Correspondence:

Dr. Anup Pradhan,

E-mail: anup0428@gmail.com

Copyright: () the author(s), publisher and licensee Medip Academy. This is an open-access article distributed under the terms of the Creative Commons Attribution Non-Commercial License, which permits unrestricted non-commercial use, distribution, and reproduction in any medium, provided the original work is properly cited.

\section{ABSTRACT}

Background: Thyroid dysfunction constitutes the second most common endocrine disorder of pregnancy, associated with adverse maternal and fetal outcome and is often overlooked in pregnancy due to their nonspecific symptoms and the hypermetabolic pregnant state. Objective of present study was to establish the prevalence of thyroid dysfunction, study the effects in pregnancy in sub-himalayan population and whether universal screening for thyroid dysfunction is required.

Methods: The study was conducted on 200 patients in the age group of 20 to 35 years with a singleton pregnancy and gestational age between 6 to 24 weeks.

Results: In the 200 women screened, the prevalence of thyroid dysfunction was found to be $14 \%$ with $8 \%$ having subclinical hypothyroidism while an equal percentage of $2 \%$ having clinical hypothyroidism, subclinical hyperthyroidism and clinical hyperthyroidism. The mean age of patients with subclinical hypothyroidism was $28.6 \pm$ 4.9 years, with thyroid disorder in pregnancy being significantly more common in primigravida. Statistically significant association was found between patients with thyroid dysfunction and abortions, preeclampsia, preterm labor, small for gestational age, low birth weight, and admission to NICU.

Conclusions: Prevalence of thyroid dysfunction was found to be high in our study, particularly subclinical hypothyroidism and was associated with adverse pregnancy outcomes; hence, more research is required in the SubHimalayan goitre belt to assess the magnitude of the problem and formulate universal screening protocols in this particular subset of the Indian population accordingly.

Keywords: Adverse pregnancy outcome, Subclinical hypothyroidism, Thyroid dysfunction, Universal screening

\section{INTRODUCTION}

In recent years considerable interest has been drawn on the role of thyroid gland and the impact of its disorder on the course of pregnancy and the neonate. Among the endocrinal dysfunction, thyroid disorder constitutes the second most common in pregnancy. ${ }^{1}$ Maternal thyroid dysfunction has been associated with adverse maternal and fetal outcome including spontaneous abortion, placental abruption, anaemia, gestational hypertension, preeclampsia, preterm labor, postpartum depression and impaired cognitive and psychomotor child development.

There has been a wide geographic variation in the prevalence of hypothyroidism in pregnancy. The prevalence of hypothyroidism in pregnancy, according to The American Congress of Obstetricians and Gynaecologist (ACOG), is 2 to $5 \%$. The prevalence of hypothyroidism appears to be more in Asian countries compared to the West. ${ }^{2}$ A very few studies from India have shown a prevalence of hypothyroidism in pregnancy 
to range from $4.8 \%$ to $11 \% .^{3}$ With this background, the study aims to find the prevalence of thyroid dysfunction in pregnancy and its maternal and fetal outcome, and whether routine screening would prove beneficial.

\section{METHODS}

This cross sectional observational study included all healthy pregnant mothers attending the out-patient department with a singleton pregnancy between the gestational ages of 6 to 26 weeks at Central Referral Hospital, the teaching hospital of Sikkim Manipal Institute of Medical Sciences; Gangtok from November 2012 to April 2014.The research proposal was approved by Institute (SMIMS) Ethical Committee. All the participating mothers were informed about the nature of the study and a written informed consent was obtained before onset of the study.

All antenatal mothers of the age group between 20 to 35 years attending the OPD, with a singleton pregnancy, irrespective of their gravida in the gestational age between 6 weeks to 24 weeks were included in the study. However, any antenatal mother with multifetal gestation, prior thyroid problems or any autoimmune disorder in pregnancy was excluded from the study.

After obtaining the gestational age and informed consent, 200 antenatal mothers were randomly selected for the study. A detailed history with particular regards to thyroid disorder, detailed physical and obstetric examination was done, on the patients fulfilling our inclusion and exclusion criteria. A single fasting serum sample was obtained, at the first booking or as early as the pregnancy was confirmed, for T3, T4, TSH. The reference range to diagnose thyroid disorder was based on American Thyroid Association guideline for diagnosis and management of thyroid disease during pregnancy and postpartum. ${ }^{1}$ Accordingly the following reference ranges that were recommended were used: first trimester -0.1 to $2.5 \mathrm{mIU} / \mathrm{l}$; second trimester -0.2 to $3.0 \mathrm{mIU} / \mathrm{l}$; third trimester -0.3 to $3.0 \mathrm{mIU} / \mathrm{l}$. Patients with abnormal thyroid results were classified as Subclinical Hypothyroidism, Clinical Hypothyroidism, Subclinical Hyperthyroidism, or Clinical Hyperthyroidism. All the patients were followed up and pregnancy outcomes variables studied in relation to abortion, Pre-eclampsia, abruptio placenta, preterm delivery, low birth weight, stillbirth, and admission to neonatal intensive care unit (NICU).

\section{Statistical analysis}

Statistical analysis was performed by the SPSS program for Windows, version 17.0. Continuous variables are presented as mean $\pm \mathrm{SD}$, and categorical variables are presented as absolute numbers and percentage. Data were checked for normality before statistical analysis using Shaipro Wilk test. Normally distributed continuous variables were compared using ANOVA. If the F value was significant and variance was homogeneous, Bonferroni multiple comparison test was used to assess the differences between the individual groups; otherwise, Tamhane's T2 test was used. Categorical variables were analyzed using the chi square test. For all statistical tests, a $\mathrm{p}$ value less than 0.05 was taken to indicate a significant difference.

\section{RESULTS}

Out of the 200 cases, 28 (14\%) showed thyroid dysfunction with $16(8 \%)$ subclinical hypothyroidism and $4(2 \%)$ each with clinical hypothyroidism, subclinical hyperthyroidism, and clinical hyperthyroidism.

Table 1: Demographic profile of pregnant women with thyroid dysfunctions.

\begin{tabular}{|c|c|}
\hline Variables & Numbers (\%) \\
\hline \multicolumn{2}{|l|}{ Age } \\
\hline 21-25 years & $4(2 \%)$ \\
\hline 26-30 years & $16(8 \%)$ \\
\hline $30-35$ years & $8(4 \%)$ \\
\hline \multicolumn{2}{|c|}{ Gravid of women } \\
\hline Primigravida & $24(85.71 \%)$ \\
\hline Multigravida & $4(14.28 \%)$ \\
\hline \multicolumn{2}{|c|}{ Gestational age } \\
\hline$<12$ weeks & $20(10 \%)$ \\
\hline 12-24 weeks & $8(4 \%)$ \\
\hline
\end{tabular}

The distribution of patients according to age was not statistically significant, with mean age of patients with subclinical hypothyroidism being $28.6 \pm 4.9$, with clinical hypothyroidism being 26.0, with subclinical hyperthyroidism being $28.5 \pm 0.7$ and clinical hyperthyroidism being $27.0 \pm 1.4$.

Table 2: Distribution of study group according to parity.

\begin{tabular}{|c|c|c|c|c|c|c|}
\hline \multirow[t]{2}{*}{ Para } & Normal & $\begin{array}{l}\text { Subclinical } \\
\text { hypothyroidism }\end{array}$ & $\begin{array}{l}\text { Clinical } \\
\text { hypothyroidism }\end{array}$ & $\begin{array}{l}\text { Subclinical } \\
\text { hyperthyroidism }\end{array}$ & $\begin{array}{l}\text { Clinical } \\
\text { hyperthyroidism }\end{array}$ & \multirow{2}{*}{$\begin{array}{l}P \\
\text { value }\end{array}$} \\
\hline & n $(\%)$ & n $(\%)$ & n $(\%)$ & n $(\%)$ & n $(\%)$ & \\
\hline 0 & $138(80.2)$ & $14(87.5)$ & $2(50)$ & $4(100)$ & $4(100)$ & \multirow{4}{*}{0.032} \\
\hline 1 & $30(17.4)$ & $2(12.5)$ & $0(0)$ & $0(0)$ & $0(0)$ & \\
\hline 2 & $4(2.3)$ & $0(0)$ & $2(50)$ & $0(0)$ & $0(0)$ & \\
\hline Total & $172(100)$ & $16(100)$ & $4(100)$ & $4(100)$ & $4(100)$ & \\
\hline
\end{tabular}


Thyroid dysfunction was significantly more prevalent in primigravida ( 24 cases) as compared to multigravida (4 cases) with an observed p value of 0.032 (Table 2).

Table 3 shows the occurrence of maternal complications in different group of patients. When compared with euthyroid case, thyroid dysfunction was significantly associated with abortions $(\mathrm{p}<0.001)$. Similarly, other complications of Preeclampsia, Preterm labor, small for gestational age, low birth weight, and admission to NICU was also significantly higher, particularly with subclinical hypothyroidism.

Table 3: Pregnancy complication in different group of patients.

\begin{tabular}{|lllllll|} 
Complications & $\begin{array}{l}\text { Euthyroid } \\
\text { n(\%) }\end{array}$ & $\begin{array}{l}\text { Subclinical } \\
\text { hypothyroidism } \\
\text { n(\%) }\end{array}$ & $\begin{array}{l}\text { Clinical } \\
\text { hypothyroidism } \\
\text { n(\%) }\end{array}$ & $\begin{array}{l}\text { Subclinical } \\
\text { hyperthyroidism } \\
\text { n(\%) }\end{array}$ & $\begin{array}{l}\text { Clinical } \\
\text { hyperthyroidism } \\
\text { n(\%) }\end{array}$ & $\begin{array}{l}\text { P } \\
\text { value }\end{array}$ \\
\hline Abortions & $0(0)$ & $4(25)$ & $0(0)$ & $2(50)$ & $2(50)$ & $<0.001$ \\
\hline Preeclampsia & $0(0)$ & $4(33.3)$ & $2(50)$ & $0(0)$ & $0(0)$ & $<0.001$ \\
\hline $\begin{array}{l}\text { Preterm } \\
\text { Small for } \\
\text { gestational age }\end{array}$ & $0(0)$ & $4(33.3)$ & $4(100)$ & $0(0)$ & $0(0)$ & $<0.001$ \\
\hline $\begin{array}{l}\text { Low birth } \\
\text { weight }\end{array}$ & $6(3.5)$ & $8(66.7)$ & $4(100)$ & $0(0)$ & $2(100)$ & $<0.001$ \\
\hline $\begin{array}{l}\text { NICU } \\
\text { admission }\end{array}$ & $1(1.2)$ & $3(50)$ & $1(50)$ & $0(0)$ & $1(100)$ & $<0.001$ \\
\hline
\end{tabular}

Table 4: Mode of delivery in different group.

\begin{tabular}{|c|c|c|c|c|c|c|}
\hline & $\begin{array}{l}\text { Euthyroid } \\
\text { n (\%) }\end{array}$ & $\begin{array}{l}\text { Subclinical } \\
\text { hypothyroidism } \\
\text { n (\%) }\end{array}$ & $\begin{array}{l}\text { Clinical } \\
\text { hypothyroidism } \\
\text { n }(\%)\end{array}$ & $\begin{array}{l}\text { Subclinical } \\
\text { hyperthyroidism } \\
\text { n }(\%)\end{array}$ & $\begin{array}{l}\text { Clinical } \\
\text { hyperthyroidism } \\
\text { n }(\%)\end{array}$ & $\begin{array}{l}P \\
\text { value }\end{array}$ \\
\hline $\begin{array}{l}\text { Vaginal } \\
\text { delivery }\end{array}$ & $110(64)$ & $10(62.5)$ & $0(0)$ & $0(0)$ & $2(50)$ & 0.154 \\
\hline $\begin{array}{l}\text { Elective } \\
\text { LSCS }\end{array}$ & $36(20.9)$ & $2(12.5)$ & $2(50)$ & $0(0)$ & $0(0)$ & 0.653 \\
\hline $\begin{array}{l}\text { Emergency } \\
\text { LSCS }\end{array}$ & $26(15.1)$ & $0(0)$ & $2(50)$ & $2(50)$ & $0(0)$ & 0.230 \\
\hline
\end{tabular}

Among 200 pregnant women screened, 110 euthyroid, 10 Subclinical Hypothyroid and 2 Clinical Hyperthyroid patients underwent normal vaginal delivery. 36 euthyroid, 2 Subclinical Hypothyroid and 2 Clinical Hypothyroid underwent elective LSCS. 26 euthyroid, 2 Clinical Hypothyroid and 2 Subclinical Hyperthyroid patients underwent emergency LSCS. The distribution was statistically insignificant $(\mathrm{p}=0.154,0.653,0.230)$. In normal group, 2 children admitted to NICU suffered from RDS. In Subclinical Hypothyroidism group, 2 children were admitted for hypoglycaemia, 2 for infection and 2 for RDS. In Clinical Hypothyroidism group, 2 children admitted to NICU had Transient Tachypnea of Newborn. In Clinical Hyperthyroidism group, 2 children admitted to NICU had RDS (Respiratory Distress Syndrome). Hence, the distribution among the study groups was statistically significant $(\mathrm{p}<0.001)$.

\section{DISCUSSION}

Thyroid disorders are among the common endocrine disorders in pregnancy with adverse maternal and fetal outcome. Early detection of thyroid dysfunction can be done if thyroid function test is suggested for in her first antenatal visit or as soon pregnancy is confirmed. ${ }^{4}$

This observational study was aimed to know the prevalence of thyroid dysfunction in pregnant women attending the antenatal clinic of a tertiary care hospital of Sikkim and see their pregnancy outcome. The results showed $14 \%$ prevalence of thyroid dysfunction with $8 \%$ subclinical hypothyroidism and $2 \%$ each of clinical hypothyroidism, subclinical hyperthyroidism, and clinical hyperthyroidism. With laboratory reference range used to detect thyroid disorders, the prevalence of thyroid disorder in this study was $14 \%$.

Present study is comparable in terms of prevalence to that done by Sahu MT et al who studied 633 women in second trimester and found prevalence of thyroid disorder as $12.7 \% .^{5}$ Our prevalence of subclinical hypothyroidism is much higher when compared to the ACOG anticipated prevalence between $2 \%$ and $5 \%{ }^{6}$ However, comparable prevalence of subclinical hypothyroidism in northern and 
southern India was reported as $6.47 \%$ and $2.8 \%$, respectively in a study by Gayathri $\mathrm{R}$ et al. ${ }^{7}$

Maternal thyroid disorder and its effect on pregnancy outcome have also been studied in western countries by many authors including Stagnaro-Green et al Negro et al and Abalovich et al. ${ }^{8-10}$ Their studies have established a strong association between thyroid disorders and adverse pregnancy outcomes.

Present study also shows statistically significant adverse pregnancy outcomes in terms of abortions, preeclampsia, preterm, small for gestational age, low birth weight and admission to NICU. Regarding mode of delivery our studies did not find any significant difference in the vaginal delivery and Cesarean delivery between euthyroid and the dysthyroid group. However, in contrast a study done by Goel et al., in 2005 found that vaginal delivery was less common and occurrence of caesarean section higher in patients with hypothyroidism and in addition hypothyroidism increased the risk of fetal distress. ${ }^{11}$

\section{CONCLUSION}

Although the body of literature on thyroid screening in pregnancy is extensive there is hardly any data based on ethnic and geographical variation. Recent guidelines, which do not recommend routine screening for thyroid function in pregnancy, are largely based on western data and application of these guidelines in an endemic setting like ours will result in missing the subclinical cases.

The prevalence of thyroid disorder especially subclinical hypothyroidism (8\%) and clinical hyperthyroidism (2\%) is common in this region.

Significant adverse maternal and fetal outcome were seen in the affected group. Hence, early detection and treatment can prevent complications in future pregnancies. Therefore, more research is required in the Sub-Himalayan goitre belt to assess the magnitude of the problem and formulate universal screening protocols in this particular subset of the Indian population accordingly.

Funding: No funding sources Conflict of interest: None declared

Ethical approval: The study was approved by the Institutional Ethics Committee

\section{REFERENCES}

1. Sahasrabuddhe A, Pitale S. Screening for thyroid dysfunction during pregnancy. Thyroid Res Pract. 2012;9:15-7.

2. Wang W, Teng W, Shan Z, Wang S, Li J, Zhu L, et al. The prevalence of thyroid disorder in early pregnancy in China: The benefits of universal screening in the first trimester of pregnancy. Eur $\mathbf{J}$ Endrocrinol. 2011;164:263-8

3. Nambiar V, Jagtap VS, Sarathi V, Lila AR, Kamalanathan S, Bandgar TR et al. Prevalence and impact of thyroid disorder on maternal outcome in Asian-Indian pregnant women. J Thyroid Res. 2011:429097

4. Banerjee S. Thyroid disorder in pregnancy. J Assoc Physicians India. 2011;59:32-4.

5. Sahu MT, Das V, Mittal S, Agarwal A, Sahu M. Overt and subclinical thyroid dysfunction among Indian pregnant women and its effect on maternal and fetal outcome. Arch Gynecol Obstet. 2010;281(2):215-20.

6. Committee on Patient Safety and Quality Improvement; Committee on Professional Liability. ACOG Committee Opinion No. 381: Subclinical hypothyroidism in pregnancy. Obstet Gynecol. 2007;110(4):959-60.

7. Gayathri R, Lavanya S, Raghavan K. Subclinical hypothyroidism and autoimmune thyoiditis in pregnancy- A study in south Indian subjects. J Assoc Physicians India. 2009;57:691-3.

8. Stagnaro-Green A. Overt hyperthyroidism and hypothyroidism during pregnancy. Clin Obstet Gynecol. 2011;54:478-87.

9. Negro R, Formoso G, Mangieri T, Pezzarossa A, Dazzi D, Hassan H. Levothyroxine treatment in euthyroid pregnant women with autoimmune thyroid disease: effects on obstetrical complications. J Clin Endocrinol Metab. 2006; 91(7):2587-91.

10. Abalovich M, Gutierrex S, Alcaraz G, Maccallini G, Garcia A, Levalle O. Overt and subclinical hypothyroidism complicating pregnancy. Thyroid. 2002;12:63-68.

11. Goel P, Raotra A, Devi K, Malhotra S, Aggarwal A, Hurria A. Maternal and perinatal outcome in pregnancy with hypothyroidism. Indian J Med Sci. 2005;59(3):116-7.

Cite this article as: Dubey S, Pradhan A. Thyroid disorder in antenatal women in sub-himalayan region: a need for universal screening. Int J Reprod Contracept Obstet Gynecol 2017;6:3445-8. 